Please do not remove this page

RMIT

UNIVERSITY

\title{
Influence of the characteristics of soluble algal organic matter released from Microcystis aeruginosa on the fouling of a ceramic microfiltration membrane
}

Zhang, Xiao Lei; Fan, Linhua; Roddick, Felicity

https://researchrepository.rmit.edu.au/esploro/outputs/9921858288901341/filesAndLinks?institution=61RMIT_INST\&index=null

Zhang, X. L., Fan, L., \& Roddick, F. (2013). Influence of the characteristics of soluble algal organic matter released from Microcystis aeruginosa on the fouling of a ceramic microfiltration membrane. Journal of Membrane Science, 425-426, 23-29. https://doi.org/10.1016/j.memsci.2012.09.033

Published Version: https://doi.org/10.1016/j.memsci.2012.09.033

Repository homepage: https://researchrepository.rmit.edu.au

(C) 2012 Elsevier B.V. All rights reserved.

Downloaded On 2023/04/26 19:50:23 +1000 
Thank you for downloading this document from the RMIT Research Repository.

The RMIT Research Repository is an open access database showcasing the research outputs of RMIT University researchers.

RMIT Research Repository: http://researchbank.rmit.edu.au/

\section{Citation:}

Zhang, X, Fan, L and Roddick, F 2013, 'Influence of the characteristics of soluble algal organic matter released from Microcystis aeruginosa on the fouling of a ceramic microfiltration membrane', Journal of Membrane Science, vol. 425426, pp. 23-29.

See this record in the RMIT Research Repository at:

http://researchbank.rmit.edu.au/view/rmit:18448

Version: Accepted Manuscript

Copyright Statement: (c) 2012 Elsevier B.V.

Link to Published Version:

http://researchbank.rmit.edu.au/view/rmit:18448 
2 released from Microcystis aeruginosa on the fouling of a ceramic microfiltration membrane 


\section{Abstract}

29 The influence of the characteristics of soluble algal organic matter (AOM) on the fouling of a

30 7-channel tubular ceramic microfiltration membrane $\left(\mathrm{ZrO}_{2}-\mathrm{TiO}_{2}, 0.1 \mu \mathrm{m}\right)$ was investigated at

31 lab scale. The AOM ( 3 mg DOC/L) extracted from a Microcystis aeruginosa culture at three

32 phases of growth (10,20 and 35 days) all caused severe flux decline, and its fouling

33 potential increased with increasing growth time. Size exclusion chromatography,

34 fluorescence excitation-emission matrix spectra and organic matter fractionation showed that

35 the high MW biopolymers were the major component determining the severity of the AOM

36 fouling of the ceramic membrane. For the AOM at stationary phase (35 days), 0.45 and $1 \mu \mathrm{m}$

37 pre-filtration gave greater flux decline and hydraulically irreversible fouling than $5 \mu \mathrm{m}$ pre-

38 filtration due to the denser foulant layer formed and greater amounts of small organic

39 molecules entering membrane pores. However, the non-pre-filtered AOM (with algal cells)

40 caused the greatest flux decline which was likely due to the presence of the high fouling

41 potential cell surface organic matter. The addition of calcium to the feed solutions led to a

42 marked improvement in flux and reduction in membrane irreversible fouling due to the lower

43 fouling potential of the AOM-calcium complexes formed.

44

45 Keywords: Algal organic matter; Ceramic membrane; Characterisation; Fouling;

46 Microfiltration 
Low pressure membrane processes such as microfiltration (MF) and ultrafiltration (UF) are being widely used for the purification of drinking water and wastewater treatment due to their high cost-effectiveness [1]. The use of ceramic MF and UF membranes for water treatment has become popular in recent years as the ceramic membranes possess many advantages over conventional polymeric membranes, such as higher selectivity, higher mechanical and chemical stability, and higher hydrophilicity [2]. However, membrane fouling remains a major drawback for most of the membrane-mediated water treatment processes, since it can lead to substantial losses of product water flux over time and the consequent great reduction in 63 the efficiency of the treatment systems [3].

Blooms of cyanobacteria (also termed blue green algae) such as Microcystis aeruginosa in increasingly eutrophic aquatic systems have become a serious environmental issue worldwide. The blooms in natural surface water and treated wastewater can result in a large amount of soluble algal organic matter $(\mathrm{AOM})$ entering downstream water treatment systems [4]. The algal organic compounds are commonly dominated by hydrophobic proteins and hydrophilic polysaccharides which have been widely regarded as responsible for the significant fouling issues in membrane filtration processes [5]. It has been demonstrated that the presence of AOM associated with natural organic matter in surface water or effluent organic matter in wastewater can further reduce the flux of polymeric MF/UF membranes [68]. Some efforts have been made since to characterise the AOM fouling of the polymeric MF/UF membranes, with a view to understanding the fouling mechanisms. Qu et al. [9] investigated the influence of the interfacial characteristics of AOM extracted from $M$. aeruginosa including surface charge, molecular size and hydrophilicity on the fouling of UF polymeric membranes. They also studied the impact of the AOM and algal cells on membrane fouling, and reported that the AOM caused greater flux decline than algal cells due to greater pore plugging and less porous cake layer formed by the AOM [10]. It was 
81 found in a further study by the research group that the dissolved AOM could cause greater

82 flux decline but less irreversible membrane fouling compared with cell surface AOM. They

83 suggested that this was because the cell surface AOM contained more large and 84 hydrophobic molecules, which could result in the foulant layer being more porous but having 85 a higher affinity to the membrane surface than dissolved AOM [11]. In another study, 86 Huang et al. [12] observed that different AOM compositions due to different nutrient 87 conditions had different impacts on the fouling of the polymeric MF membranes. The high 88 fouling potential of AOM was attributed to the high molecular weight polysaccharide-like and 89 proteinaceous substances.

91 Although great attention has been drawn to the application of ceramic membranes in water 92 and wastewater treatment, the information regarding $\mathrm{AOM}$ fouling of these membranes is 93 very limited to date. A better understanding of AOM fouling of ceramic membranes (which 94 are significantly different from polymeric membranes in terms of physical, chemical and 95 mechanical properties) is essential for the effective design and operation of the processes. 96 As such, the aim of this study was to investigate the impact of the characteristics of soluble 97 AOM on the fouling of a commercially available ceramic MF membrane at lab scale. The 98 influence of the AOM from different phases of $M$. aeruginosa growth, feed solution pre99 filtration, and the presence of calcium ions on the fouling was investigated. Advanced 100 organic matter characterisation techniques including size exclusion chromatography (SEC) 101 using liquid chromatography with organic carbon detection (LC-OCD), fluorescence 102 excitation-emission matrix (EEM) spectra and fractionation using resin adsorption 103 chromatography were employed to gain a better insight into the characteristics of the organic 104 compounds involved.

105

106

107 


\section{Experimental}

109

2.1. Cultivation of algae, AOM extraction and preparation of feed solutions

M. aeruginosa (CS 566/01-A01) was purchased from the CSIRO Microalgae Research

112 Centre (Tasmania, Australia). The algal cultures were grown in $5 \mathrm{~L}$ Schott bottles at $22{ }^{\circ} \mathrm{C}$

113 using MLA medium [13] under humidified aeration. A 16/8 hour light/dark cycle was used to

114 simulate natural light conditions. According to several reports, the algae have high 115 absorbance at $684 \mathrm{~nm}$ [14-16]. Optical density (OD) of the algal cell suspension was 116 therefore used to measure algal cell concentration. The correlation between $\mathrm{OD}_{684}$ and cell 117 count $\left(5 \times 10^{3}-5 \times 10^{6}\right.$ cells $\left.\mathrm{mL}^{-1}\right)$ was verified as indicated by their strong linear relationship $118\left(R^{2}>0.99\right)$ (data not shown).

Algal cultures were harvested at the 10th (early exponential phase), 20th (late exponential phase) and 35th day (stationary phase) of growth. Centrifugation (3270 $\times \mathrm{g}$ for $30 \mathrm{mins})$ of the algal cell suspensions and the subsequent filtration of the supernatant (using $1 \mu \mathrm{m}$ membranes unless otherwise stated) were conducted to extract the dissolved extracellular

124 AOM $[8,9]$. In the preparation of the MF feed solutions, the extracted AOM was diluted to approximately the same dissolved organic carbon (DOC) concentration $(5.0 \pm 0.2 \mathrm{mg} / \mathrm{L})$ with tap water $(1.9 \pm 0.05 \mathrm{mg} \mathrm{DOC/L})$. The $\mathrm{pH}$ of the MF feed solution was adjusted to $8.0 \pm 0.2$ using $1 \mathrm{M} \mathrm{HCl}$ or $1 \mathrm{M} \mathrm{NaOH}$ prior to each filtration run.

2.2. Ceramic membrane filtration rig

130 A 7-channel tubular ceramic $\mathrm{ZrO}_{2}-\mathrm{TiO}_{2}$ MF membrane with a nominal pore size of $0.1 \mu \mathrm{m}$ 131 (CeRAM $^{\mathrm{TM}}$ INSIDE, TAMI Industries) was used in the filtration experiments. The active layer 132 of this membrane is made of a mixture of $\mathrm{ZrO}_{2}$ and $\mathrm{TiO}_{2}$, and the support layer is made of $133 \mathrm{TiO}_{2}$. These materials give the membrane a highly hydrophilic nature which can reduce the 134 fouling potential to some extent. According to the manufacturer, the membrane can be 135 operated at high temperature (up to $350{ }^{\circ} \mathrm{C}$ ) and is insensitive to bases and acids. A 
136 schematic diagram of the lab-scale ceramic membrane system is presented in Fig. 1. The rig

137 can be operated in either dead-end or cross-flow mode by closing or opening the

138 downstream valve (Valve 3). All filtration runs were carried out in inside-out and dead-end 139 modes at a constant transmembrane pressure (TMP) of $70 \pm 1 \mathrm{kPa}$ and under room

140 temperature $\left(22 \pm 2{ }^{\circ} \mathrm{C}\right)$. Membrane backwashing was carried out by filtering tap water in

141 outside-in operation mode (i.e., closing Valves 1 and 4, opening Valves 2 and 3) at the same

142 TMP as the filtration runs.

144 Fig. 1. Schematic diagram of the ceramic membrane filtration system, P1, P2, P3 are manometers.

147 2.3. Microfiltration test

148 Prior to each MF run, the clean water flux of the clean membrane $\left(J_{0}\right)$ was obtained by 149 filtering tap water for 2 minutes. The AOM solution was then filtered for 90 minutes under the 150 defined conditions. Membrane permeate flow rate was recorded continuously, and the 151 permeate was sampled after 15, 30, 60 and 90 minutes filtration for chemical analyses. After 152 AOM solution filtration, the clean water flux of the fouled membrane $\left(J_{a}\right)$ was determined by 153 filtering tap water for 2 minutes. The membrane was then backwashed for 2 minutes, and 154 the clean water flux of the backwashed membrane $\left(J_{b}\right)$ was measured by filtering tap water 155 for 2 minutes. Reversible fouling (RF), an indicator of the affinity of foulant for the membrane, 156 was estimated using the following equation (Eq. (1)) [17]. The series resistances including 157 reversible $\left(R_{r}\right)$ and irreversible filtration resistance $\left(R_{i}\right)$ were also calculated using the 158 method described elsewhere [18].

$$
R F=\frac{J_{b}-J_{a}}{J_{0}-J_{a}} \times 100 \%
$$


163 The same membrane was used for all MF runs, and after each run the membrane was

164 restored by Cleaning in Place (CIP) until the permeate flux reached 138-148 LMH. CIP was 165 carried out through the following steps: 1) $0.1 \mathrm{M} \mathrm{NaOH}$ solution $\left(65^{\circ} \mathrm{C}\right)$ for 30 minutes; 2) $1660.1 \mathrm{M} \mathrm{HNO}_{3}$ solution $\left(65^{\circ} \mathrm{C}\right)$ for 20 minutes; 3$)$ tap water $\left(18-20{ }^{\circ} \mathrm{C}\right)$ for 2 minutes. All 167 filtration tests were run in duplicate. As the final flux of the duplicate tests typically agreed 168 within $5 \%$ and the trend was found to be consistent between the duplicate runs, only one set 169 of flux data was reported. Reversible fouling results were reported using average values.

2.4. Analytical methods

172 DOC was determined using a Sievers 820 TOC analyser. $U_{V A} A_{254}$ and $\mathrm{OD}_{684}$ were measured 173 using a UV/vis spectrophotometer (UV2, Unicam). The $\mathrm{pH}$ was measured using a Hach 174 Sension $156 \mathrm{pH}$ meter. The concentration of calcium was measured with an atomic 175 absorption spectrometer (AA240FS, Varian). Apparent molecular weight distribution of the 176 AOM was determined by SEC with LC-OCD at the Water Research Centre of the University 177 of New South Wales, Sydney, Australia. The LC-OCD system (LC-OCD Model 8, DOC178 Labor Dr. Huber, Germany) utilised a SEC column (Toyopearl TSK HW-50S, diameter $2 \mathrm{~cm}$, 179 length $25 \mathrm{~cm}$ ) and the chromatograms were processed using the Labview based program 180 Fiffikus (DOC-Labor Dr. Huber, Germany). Fluorescence excitation-emission matrix (EEM) 181 spectra were obtained using a fluorescence spectrometer (LS 55, PerkinEImer) at an 182 excitation and emission wavelength range of $200-550 \mathrm{~nm}$. In order to remove the Raman 183 scatter and other background noise, the fluorescence spectra of Milli-Q water were 184 subtracted from all EEM spectra using Origin software. Fractionation using XAD-4 and DAX1858 resins was used to separate the organics into hydrophobic (HPO), transphilic (TPI), and 186 hydrophilic (HPI) fractions [19]. 


\section{Results and discussion}

192

193

3.1. Influence of AOM from different phases of $M$. aeruginosa growth

194

\subsubsection{Flux decline and reversibility of AOM fouling}

195 Rapid flux decline was observed during the MF of the solutions containing the AOM 196 extracted at 10, 20 and 35 days of M. aeruginosa growth, with the majority of flux decline 197 occurring before the specific permeate volume reached $30 \mathrm{~L} / \mathrm{m}^{2}$ (Fig. 2). In the initial stage of 198 the filtration $\left(<30 \mathrm{~L} / \mathrm{m}^{2}\right)$, the solution containing Day $35 \mathrm{AOM}$ gave a much more rapid and 199 greater flux reduction compared with Day 10 and Day 20 AOM. The maximum flux decline was reached at about $40 \mathrm{~L} / \mathrm{m}^{2}$ for the Day $35 \mathrm{AOM}$, whereas Day 10 and Day $20 \mathrm{AOM}$ solutions led to continued flux reduction until the runs were terminated. On reaching $80 \mathrm{~L} / \mathrm{m}^{2}$, Day 20 AOM exhibited a similar flux to Day 35 AOM, which was about 5\% greater than Day 10 AOM. Control filtration tests with tap water and MLA solution (the concentration of MLA in tap water was the same as that in the Day 10 AOM solution) showed the flux decline was relatively insignificant compared with the AOM solutions. The impact of the organic matter in the tap water and MLA on the membrane performance was therefore considered negligible in this study.

208

209

The extent of reversible fouling by the AOM decreased with increasing $M$. aeruginosa growth time, with 35\% for Day $10\left(R_{r} 39.4 \times 10^{10} \mathrm{~m}^{-1}, R_{i} 48.9 \times 10^{10} \mathrm{~m}^{-1}\right), 17 \%$ for Day $20\left(R_{r} 27.7 \times\right.$ $\left.10^{10} \mathrm{~m}^{-1}, R_{i} 82.8 \times 10^{10} \mathrm{~m}^{-1}\right)$ and $10 \%$ for Day $35\left(R_{r} 18.3 \times 10^{10} \mathrm{~m}^{-1}, R_{i} 103.9 \times 10^{10} \mathrm{~m}^{-1}\right)$.

212 Hence the AOM obtained from a later phase of algal growth had higher affinity for the 213 ceramic membrane compared with the AOM from an earlier growth phase, and consequently 214 led to more severe irreversible membrane fouling.

Fig. 2. Normalized flux vs. specific volume for the MF of tap water, MLA solution and the solutions containing AOM from different phases of $M$. aeruginosa growth. 


\subsubsection{AOM rejection by the ceramic MF membrane}

220 DOC rejection for the AOM from the three phases of $M$. aeruginosa growth was similar (31$35 \%$ ), and the DOC rejection for each $\mathrm{AOM}$ sample was fairly consistent (variation $2-4 \%$ ) over the filtration period (Fig. 3). A similar trend was observed for $U_{V A} A_{25}$ rejection (16-20\%), however the UVA rejection was markedly lower than DOC rejection. This indicated that the organic matter retained by the membrane contained less UV-absorbing organic materials. As suggested by Zheng et al. [20], the retained organic matter could contain a large portion of biopolymer substances in the AOM, such as proteins and polysaccharides.

227

Fig. 3. DOC and $\mathrm{UVA}_{254}$ rejection during MF of the three AOM solutions.

\subsubsection{Characterisation of the AOM by LC-OCD}

In order to interpret the diverse fouling behaviour of the AOM from the different phases of algal growth, the molecular weight distribution of the AOM was examined using SEC with LC-OCD (Fig. 4). Day 10 AOM contained significantly less high MW organic components such as biopolymers (> 20,000 Da) and humic-like substances (500-20,000 Da), but more medium-MW components (i.e., building blocks, 350-500 Da), low MW acids and low MW humic substances (<350 Da) compared with Day 20 and Day 35 AOM. Although Day 35 AOM had a similar content of biopolymers and low-MW compounds to the Day $20 \mathrm{AOM}$, it contained significantly more humic-like substances.

Biopolymers such as polysaccharides and proteins have been proven to result in severe fouling of polymeric MF membranes [1, 21]. On the other hand, the deposition of humic substances via hydrophobic interaction with the surface of membranes can also lead to significant membrane fouling [22]. The flux and reversible fouling results presented in section

2443.1 .2 were therefore related to the relative content of the high MW organic compounds 245 (biopolymers and humic-like substances) in the AOM derived from the different phases of 246 algal growth. The lower fouling potential for the AOM from the early exponential phase (Day 
247 10) was due to the lower content of biopolymers and high MW humic-like substances. The 248 greater fouling potential of Day 35 AOM compared with Day 20 AOM was associated with a 249 greater amount of high MW humic-like substances, which could result in an enhanced 250 fouling effect on the membrane as reported by Yuan and Zydney [22]. However, it may also 251 be possible that the different fouling behaviour of the Day 20 and Day 35 AOM was due to 252 the different chemical compositions of their biopolymers.

253

254

Fig. 4. LC-OCD chromatograms of the AOM from different phases of $M$. aeruginosa growth. 255 $\mathrm{HS}=$ humic substances.

\subsubsection{Characterisation of $A O M$ by fluorescence EEM spectra}

257 Fluorescence EEM spectra are widely used for the characterisation of fluorescent organic 258 components in natural organic matter or wastewater effluent organic matter. According to 259 Chen et al. [23], EEM spectra can be divided into 5 regions (Fig. 5a). Regions I (Ex/Em: $260220-270 \mathrm{~nm} / 280-330 \mathrm{~nm}$ ) and II (Ex/Em: 220-270 nm/330-380 nm) correspond to aromatic 261 proteins, and region III (Ex/Em: $220-270 \mathrm{~nm} / 380-540 \mathrm{~nm}$ ) is associated with fulvic acid (FA)262 like substances. Regions IV (Ex/Em: 270-440 nm/280-380 nm) and V (Ex/Em: 270-440 263 $\mathrm{nm} / 380-540 \mathrm{~nm}$ ) represent soluble microbial products (SMPs, e.g., proteins and polysaccharide-like materials) and humic acid (HA)-like materials, respectively. The AOM extracts for the different phases of $M$. aeruginosa growth exhibited different EEM spectral features (Figs. 5a, b \& c). The fluorophores increased with increasing $M$. aeruginosa growth

267 time in all EEM regions, which was likely due to the changes in molecular weight/size 268 distribution and/or chemical composition of the AOM over the algal growth phases, i.e., from lower MW to higher MW as shown in Fig. 4. There was a marked increase in fluorescence

270 for all regions between the late exponential (20 days) and the stationary phase (35 days) 271 (Figs. 5b \& c).

272 
273 The fluorescence regional integration (FRI) method [23] was used to quantify the changes in

274 the fluorescent organic species before and after the MF runs in terms of EEM spectra (EEMs)

275 volume in each region (Fig. 6). The EEMs volumes of the tap water before and after MF are

276 provided as a reference. The EEMs volumes for the HA-like and FA-like regions of the

277 organic matter in Day 10 AOM solution was mainly contributed by the organic matter in the

278 tap water, whereas almost all of the aromatic proteins (AP) and SMPs in the solution were

279 contributed by the AOM. After MF, the reductions in EEMs volume in all five regions for Day

28010 AOM were markedly lower than for Day 20 and Day 35 AOM. This suggested that less

281 organic matter associated with these regions for the Day $10 \mathrm{AOM}$ was retained by the

282 membrane, and hence led to less fouling of the membrane. The lower rejection of these

283 fluorescent organic components was attributed to the relative abundance of low MW

284 compounds in the early phase of $M$. aeruginosa growth (Fig. 4). There were considerably

285 greater reductions in EEMs volumes in both the AP and SMPs regions for Day 35 AOM and

286 Day 20 AOM (i.e., 66\% and 39\% for AP, 38\% and 24\% for SMPs, respectively) compared

287 with the reductions in the FA-like and HA-like regions (i.e., $34 \%$ and $18 \%$ for FA-like, $18 \%$

288 and $5 \%$ for HA, respectively). This indicated that aromatic proteins and SMP-like substances

289 were the major fouling organic components of the ceramic MF membrane. It should be noted

290 that a considerably greater amount of humic substances in the Day 35 AOM was retained by

291 the membrane compared with Day 20 AOM, this could also play a role in the enhanced

292 membrane fouling for the Day 35 AOM.

293

Fig. 5. Fluorescence EEM spectra of (a) Day 10, (b) Day 20 and (c) Day 35 AOM.

297

Fig. 6. EEM spectra volumes for the AOM before and after MF. 
302 The AOM before and after microfiltration was fractionated into different organic groups using 303 resin adsorption chromatography, and the results are presented in Fig. 7 in terms of DOC 304 concentrations. Day 10 AOM contained significantly more hydrophobic (HPO) but less

305 transphilic compounds (TPI), and its hydrophilic fraction (HPI) was only slightly lower than

306 Day 20 and 35 AOM. Although the rejection of bulk DOC was similar for the three AOM 307 samples (Fig. 3), the rejection of their fractions varied significantly. There were greater 308 reductions in HPO (38\%) and TPI (34\%) fractions for the Day 10 AOM after MF compared 309 with Day 20 (29\% HPO and 19\% TPI) and Day 35 AOM (33\% HPO and 23\% TPI). However, 310 there was significantly less reduction in HPI (29\%) for Day 10 AOM compared with Day 20 311 and Day 35 AOM which had 46 and $63 \%$ reduction, respectively. The results suggested that $312 \mathrm{HPI}$ had greater fouling potential than the HPO and TPI fractions, as the greater retention of $313 \mathrm{HPO}$ and TPI for Day $10 \mathrm{AOM}$ did not result in poorer membrane performance compared 314 with Day 20 or Day 35 AOM. This was consistent with some previous studies where the 315 hydrophilic organic fraction that contained a greater proportion of high MW compounds such

316 as biopolymers was found to have higher fouling potential compared with hydrophobic (such 317 as humic substances) and transphilic compounds [1, 18].

319 Although the HPI content was only slightly higher for Day 35 AOM than Day 10 and Day 20 $\mathrm{AOM}$, there was a markedly greater retention of this fraction for the Day $35 \mathrm{AOM}(63 \% \mathrm{cf}$. $32146 \%$ Day 20 and 29\% Day 10). This indicated that the composition/physico-chemical 322 properties of the HPI fractions in the three AOM samples were markedly different, and hence 323 they exhibited different fouling behaviour. It has been reported that the AOM derived from the 324 stationary phase of $M$. aeruginosa contained more hydrophilic biopolymer substances (i.e., hydrophilic proteins and carbohydrates) compared with the AOM in the exponential growth 326 phase [24]. Therefore, the increased fouling by the AOM derived from a later algal growth 327 phase in our study was attributed to the hydrophilic biopolymers, which had greater fouling 328 potential compared with the other fractional components in the AOM. 
330 Fig. 7. Fractional components of AOM in MF feed and permeate. HPO: hydrophobic fraction; TPI: transphilic fraction; HPI: hydrophilic fraction.

332

333 3.2. Influence of AOM pre-filtration

334 The impact of pre-filtration of the AOM on the fouling of the ceramic MF membrane was 335 studied by comparing the flux decline and reversible fouling for $0.45,1$ and $5 \mu \mathrm{m}$ pre-filtered $336 \mathrm{AOM}$ and non-pre-filtered AOM (with M. aeruginosa cells) (Fig. 8). The AOM after $5 \mu \mathrm{m}$ pre337 filtration gave significantly less flux reduction during the whole filtration period compared with 338 the other feed solutions. It was observed that around $70 \%$ of the algal cells were removed by $3395 \mu \mathrm{m}$ pre-filtration (data not shown), and the lower flux reduction for the $5 \mu \mathrm{m}$ pre-filtered 340 AOM indicated that the remaining particulates (including the smaller algal cells) formed a 341 fouling layer with lower filtration resistance. The 0.45 and $1 \mu \mathrm{m}$ filtered AOM caused a 342 similar flux decline over the filtration period, which was likely due to these two pre-filtration 343 membranes being relatively similar in pore size and hence their filtrates would have similar 344 physico-chemical properties. However, the non-pre-filtered AOM produced the greatest flux 345 decline which suggested that the algal cell-AOM and/or cell-membrane interactions could 346 have played an influential role in the fouling of the ceramic MF membrane.

348 The above results imply that both dissolved $\mathrm{AOM}(<0.45$ or $1 \mu \mathrm{m})$ and the particulates in the 349 AOM solutions can affect the filtration process. The dissolved AOM can cause much more rapid and greater flux decline due to the resultant denser fouling layer, and the presence of 351 particulates can alleviate the initial rapid flux decline due to the formation of a more porous 352 layer of lower resistance. However, the particulates can build up on the membrane surface 353 and make the fouling layer thicker as the filtration proceeds, and hence increase the filtration 354 resistance, leading to greater further reduction in flux at the later stage of filtration (e.g., after $35540 \mathrm{~L} / \mathrm{m}^{2}$ for the $5 \mu \mathrm{m}$ pre-filtered $\mathrm{AOM}$ ). In addition, the AOM attached to the algal cells 
356 (also termed cell surface AOM or bound extracellular organic matter) could cause linkages

357 between the cells, leading to a more compact cake layer under the system pressure and 358 hence greater reduction in flux [25].

359

360

361

362

363

Fig. 8. Normalized flux vs. specific volume for the MF of the solutions of: 1) AOM with cells; 2) $0.45 \mu \mathrm{m}$ pre-filtered $\mathrm{AOM}$; 3) $1.0 \mu \mathrm{m}$ pre-filtered $\mathrm{AOM}$; 4) $5.0 \mu \mathrm{m}$ pre-filtered $\mathrm{AOM}$. (All feed solutions contained AOM extracted from stationary phase)

364 It was observed that the $5 \mu \mathrm{m}$ pre-filtered AOM gave the highest reversible fouling (around $\left.36521 \%, R_{r} 43.9 \times 10^{10} \mathrm{~m}^{-1}, R_{i} 97.8 \times 10^{10} \mathrm{~m}^{-1}\right)$. This was likely due to the loosely bonded "pre366 layer" formed by the particulates which can prevent smaller particulates from entering the 367 membrane pores, and hence lead to reduced irreversible fouling. As a comparison, only 8$36810 \%$ reversible fouling $\left(R_{r} 24.6 \times 10^{10} \mathrm{~m}^{-1}, R_{i} \quad 119.9 \times 10^{10} \mathrm{~m}^{-1}\right)$ was obtained for the AOM 369 pre-filtered by the 0.45 or $1 \mu \mathrm{m}$ filters. The non-pre-filtered AOM solution (i.e., with cells) also 370 produced lower reversible fouling $\left(10 \%, R_{r} 25.8 \times 10^{10} \mathrm{~m}^{-1}, R_{i} 128.9 \times 10^{10} \mathrm{~m}^{-1}\right)$. This was

371 likely due to the presence of the algal cell surface AOM which was reported to have higher 372 potential for irreversible membrane fouling compared with the dissolved AOM [11].

3.3. Influence of calcium ion

375 In order to get further insights into the interfacial characteristics of the AOM, calcium (i.e., $376 \mathrm{CaCl}_{2}$ ) of different concentrations was added to feed solutions containing stationary phase 377 AOM. Addition of calcium reduced the flux decline markedly (Fig. 9), with $2.5 \mathrm{mM}$ of calcium 378 giving slightly greater flux improvement compared with other dosages. As noted by Qu et al. 379 [9], the addition of calcium increased the AOM molecular sizes due to complexation. A 380 significant amount of calcium was retained by the membrane at all dosages, i.e., 17.5 $38149.7 \%$ (Table 1), which indicated the formation of large complexes of calcium ions and the 382 AOM (i.e., > $0.1 \mu \mathrm{m}$ ). The large AOM complexes would then form a more porous pre-layer 383 and so result in a higher filtration flux. It was observed that the addition of calcium also led to 384 increased reversible fouling at all calcium dosages (from $11 \%$ to $20-25 \%, R_{r}$ from $18.3 \times 10^{10}$ 
$\mathrm{m}^{-1}$ to $\sim 43.7 \times 10^{10} \mathrm{~m}^{-1}, R_{i}$ from $103.9 \times 10^{10} \mathrm{~m}^{-1}$ to $\left.77.7 \times 10^{10}-97.8 \times 10^{10} \mathrm{~m}^{-1}\right)$. At $10 \mathrm{mM}$

386 calcium, there was less flux improvement. This was most probably due to the increased

387 amount of AOM-calcium complexes (as indicated by the increased calcium retention at 10

$388 \mathrm{mM}$ ), which would result in a thicker cake layer and hence higher resistance to the filtration.

390 The DOC retained by the ceramic membrane during MF of the feed solution without addition 391 of calcium was slightly higher than the feed with the calcium addition at $1.0,2.5$ or $5.0 \mathrm{mM}$

392 (Table 1). This was attributed to the denser fouling layer formed by the AOM solution (no 393 calcium addition), which led to the greater retention of some AOM molecules compared with

394 the more porous layer formed by the AOM-calcium complexes. However, the calcium 395 dosage at $10 \mathrm{mM}$ resulted in a greater DOC retention compared with the feed without 396 calcium addition. This could be due to the trapping of some AOM molecules by the resultant 397 thicker fouling layer and/or the increased complexation of the AOM at the high calcium 398 dosage. It is known that at high calcium concentration aquatic organic matter becomes insoluble when maximum complexation is attained [26].

Fig. 9. Normalized flux vs. specific volume for the MF of AOM (stationary phase) solutions with and without addition of calcium.

403

Table 1. Retention of calcium and DOC by the ceramic MF membrane at different calcium

\section{Conclusions}

409

410 The influence of the soluble AOM extracted from three different phases of $M$. aeruginosa 411 growth, AOM pre-filtration and the presence of calcium ion on the fouling of a $0.1 \mu \mathrm{m} \mathrm{ZrO}_{2}$ $412 \mathrm{TiO}_{2}$ ceramic MF membrane was studied. AOM from the different algal growth phases all 
413 caused rapid and great flux decline, but exhibited different fouling potentials, with fouling for

414 the stationary phase $>$ late exponential phase $>$ early exponential phase. Characterisation of

415 the AOM using SEC with LC-OCD, fluorescence EEMs and organic matter fractionation

416 indicated that the biopolymers (containing mainly proteinaceous materials and

417 polysaccharides) were the major organic component that determined the severity of the

418 AOM fouling of the ceramic MF membrane. Since the amount of biopolymer in the late

419 exponential and the stationary phase AOM was fairly similar, it is suggested that a difference

420 in the properties of the biopolymers led to the higher fouling potential of the stationary phase

421 AOM.

422

423 For the stationary phase, the soluble AOM (i.e., 0.45 or $1 \mu \mathrm{m}$ pre-filtered) caused more rapid

424 flux decline compared with the $5 \mu \mathrm{m}$ pre-filtered AOM. The relatively lower flux decline for

425 the $5 \mu \mathrm{m}$ pre-filtered AOM was attributed to a more porous foulant layer due to the presence

426 of particulates in the feed solution. However, the non-pre-filtered AOM (with algal cells)

427 produced the greatest flux reduction, which was likely due to the presence of the high fouling

428 potential cell surface organics. The addition of calcium to the AOM solutions led to reduced

429 flux decline and increased reversible fouling due to complexation of the calcium ions with the

430 AOM molecules to form large complexes and consequently a more porous foulant layer on

431 the membrane surface.

432

433 The results indicate that monitoring algal growth can be important for the effective prediction

434 of fouling and implementation of maintenance measures for ceramic membrane systems

435 during cyanobacterial bloom events. Removal of cyanobacterial cells by a loose MF pre-filter

436 (e.g., $5 \mu \mathrm{m}$ ) may mitigate membrane fouling due to the reduction of the cell surface organic

437 matter. Furthermore, chemical coagulation may be an effective pre-treatment of AOM

438 containing water for improving the filtration performance of the ceramic MF membranes

439 since the fouling potential of $\mathrm{AOM}$ can be greatly reduced by its complexation with metal 440 ions. 


\section{References}

443

444 [1] N. Lee, G. Amy, J.-P. Croué, H. Buisson, Identification and understanding of fouling in 445 low-pressure membrane (MF/UF) filtration by natural organic matter (NOM), Water Res. $446 \quad 38(2004) 4511-4523$.

447 [2] B. Hofs, J. Ogier, D. Vries, E.F. Beerendonk, E.R. Cornelissen, Comparison of ceramic 448 and polymeric membrane permeability and fouling using surface water, Sep. Purif. $449 \quad$ Technol. $79(2011) 365-374$.

450 [3] P. Bacchin, P. Aimar, R.W. Field, Critical and sustainable fluxes: Theory, experiments $451 \quad$ and applications, J. Membr. Sci. 281 (2006) 42-69.

452 [4] J. Fang, X. Yang, J. Ma, C. Shang, Q. Zhao, Characterization of algal organic matter and 453 formation of DBPs from chlor(am)ination, Water Res.44 (2010) 5897-5906.

454 [5] Y.-T. Chiou, M.-L. Hsieh, H.-H. Yeh, Effect of algal extracellular polymer substances on 455 UF membrane fouling, Desalination 250 (2010) 648-652.

456 [6] N. Lee, G. Amy, J.-P. Croué, Low-pressure membrane (MF/UF) fouling associated with 457 allochthonous versus autochthonous natural organic matter, Water Res. 40 (2006) 23574582368.

459 [7] Y. Goh, J. Harris, F. Roddick, Impact of Microcystis aeruginosa on membrane fouling in a 460 biologically treated effluent, Water Sci. Technol. 63 (2011) 2853-2859.

461 [8] Y. Goh, J. Harris, F. Roddick, Reducing the effect of cyanobacteria in the microfiltration of 462 secondary effluent, Water Sci. Technol. 62 (2010) 1682.

463 [9] F. Qu, H. Liang, Z. Wang, H. Wang, H. Yu, G. Li, Ultrafiltration membrane fouling by 464 extracellular organic matters (EOM) of Microcystis aeruginosa in stationary phase: 465 Influences of interfacial characteristics of foulants and fouling mechanisms, Water Res. $466 \quad 46(2012) 1490-1500$. 
467 [10] F. Qu, H. Liang, J. Tian, H. Yu, Z. Chen, G. Li, Ultrafiltration (UF) membrane fouling 468 caused by cyanobateria: Fouling effects of cells and extracellular organics matter (EOM), 469 Desalination 293 (2012) 30-37.

470 [11] F. Qu, H. Liang, J. He, J. Ma, Z. Wang, H. Yu, G. Li, Characterization of dissolved 471 extracellular organic matter (dEOM) and bound extracellular organic matter (bEOM) of 472 Microcystis aeruginosa and their impacts on UF membrane fouling, Water Res. 46 (2012) $473 \quad 2881-2890$.

474 [12] W. Huang, H. Chu, B. Dong, Characteristics of algogenic organic matter generated 475 under different nutrient conditions and subsequent impact on microfiltration membrane 476 fouling, Desalination 293 (2012) 104-111.

477 [13] C. Bolch, S. Blackburn, Isolation and purification of Australian isolates of the toxic $478 \quad$ cyanobacterium Microcystis aeruginosa Kütz, J. Appl. Phycol. 8 (1996) 5-13.

479 [14] P. Rajasekhar, L. Fan, T. Nguyen, F.A. Roddick, Impact of sonication at $20 \mathrm{kHz}$ on 480 Microcystis aeruginosa, Anabaena circinalis and Chlorella sp, Water Res. 46 (2012) $481 \quad$ 1473-1481.

482 [15] G. Zhang, P. Zhang, H. Liu, B. Wang, Ultrasonic damages on cyanobacterial 483 photosynthesis, Ultrason. Sonochem. 13 (2006) 501-505.

484 [16] G. Zhang, P. Zhang, B. Wang, H. Liu, Ultrasonic frequency effects on the removal of 485 Microcystis aeruginosa, Ultrason. Sonochem. 13 (2006) 446-450.

486 [17] M. Hashino, K. Hirami, T. Katagiri, N. Kubota, Y. Ohmukai, T. Ishigami, T. Maruyama, H. 487 Matsuyama, Effects of three natural organic matter types on cellulose acetate butyrate 488 microfiltration membrane fouling, J. Membr. Sci. 379 (2011) 233-238.

489 [18] L. Fan, J.L. Harris, F.A. Roddick, N.A. Booker, Influence of the characteristics of natural $490 \quad$ organic matter on the fouling of microfiltration membranes, Water Res. 35 (2001) 44554914463.

492 [19] G.R. Aiken, D.M. McKnight, K.A. Thorn, E.M. Thurman, Isolation of hydrophilic organic 493 acids from water using nonionic macroporous resins, Org. Geochem. 18 (1992) 567-573. 
494 [20] X. Zheng, M. Ernst, M. Jekel, Identification and quantification of major organic foulants 495 in treated domestic wastewater affecting filterability in dead-end ultrafiltration, Water Res. $496 \quad 43(2009)$ 238-244.

497 [21] C.N. Laabs, G.L. Amy, M. Jekel, Understanding the Size and Character of Fouling498 Causing Substances from Effluent Organic Matter (EfOM) in Low-Pressure Membrane $499 \quad$ Filtration, Environ. Sci. Technol. 40 (2006) 4495-4499.

500 [22] W. Yuan, A.L. Zydney, Humic acid fouling during microfiltration, J. Membr. Sci. 157 $501 \quad$ (1999) $1-12$.

502 [23] W. Chen, P. Westerhoff, J.A. Leenheer, K. Booksh, Fluorescence Excitation-Emission 503 Matrix Regional Integration to Quantify Spectra for Dissolved Organic Matter, Environ. $504 \quad$ Sci. Technol. 37 (2003) 5701-5710.

505 [24] R.K. Henderson, A. Baker, S.A. Parsons, B. Jefferson, Characterisation of algogenic 506 organic matter extracted from cyanobacteria, green algae and diatoms, Water Res. 42 $507 \quad$ (2008) 3435-3445.

508 [25] S. Babel, S. Takizawa, Microfiltration membrane fouling and cake behavior during algal 509 filtration, Desalination 261 (2010) 46-51.

510 [26] S. Hong, M. Elimelech, Chemical and physical aspects of natural organic matter (NOM) 511 fouling of nanofiltration membranes, J. Membr. Sci. 132 (1997) 159-181. 
523 Table 1. Retention of calcium and DOC by the ceramic MF membrane at different calcium dosages.

\begin{tabular}{lll}
\hline Calcium dosage $(\mathrm{mM})$ & Calcium retention (\%) & DOC retention (\%) \\
\hline 0 & - & 36.5 \\
1.0 & 17.5 & 33.4 \\
2.5 & 37.0 & 31.8 \\
5.0 & 42.5 & 32.3 \\
10.0 & 49.7 & 41.1 \\
\hline
\end{tabular}

525

526

527

528

529

530

531

532

533

534

535

536

537

538

539

540

541

542 


\section{Figure Captions}

544

545 Fig. 8. Schematic diagram of the ceramic membrane filtration system, P1, P2, P3 are manometers.

547 Fig. 9. Normalized flux vs. specific volume for the MF of tap water, MLA solution and the solutions containing AOM from different phases of $M$. aeruginosa growth.

549 Fig. 10. DOC and $\mathrm{UVA}_{254}$ rejection during MF of the three AOM solutions.

550 Fig. 11. LC-OCD chromatograms of the AOM from different phases of $M$. aeruginosa growth. HS = humic substances.

552 Fig. 12. Fluorescence EEM spectra of (a) Day 10, (b) Day 20 and (c) Day 35 AOM. Regions I and II: aromatic proteins (AP); Region III: fulvic acid-like (FA); Region IV: soluble microbial products (SMPs); Region V: humic acid-like (HA)

Fig. 13. EEM spectra volumes for the AOM and tap water before and after MF.

556 Fig. 14. Fractional components of AOM in MF feed and permeate. HPO: hydrophobic fraction; TPI: transphilic fraction; HPI: hydrophilic fraction.

558 Fig. 15. Normalized flux vs. specific volume for the MF of the solutions of: 1) AOM with cells; 2) $0.45 \mu \mathrm{m}$ pre-filtered $\mathrm{AOM}$; 3) $1.0 \mu \mathrm{m}$ pre-filtered $\mathrm{AOM}$; 4) $5.0 \mu \mathrm{m}$ pre-filtered $\mathrm{AOM}$. (All feed solutions contained AOM extracted from stationary phase)

Fig. 16. Normalized flux vs. specific volume for the MF of AOM (stationary phase) solutions with and without addition of calcium. 


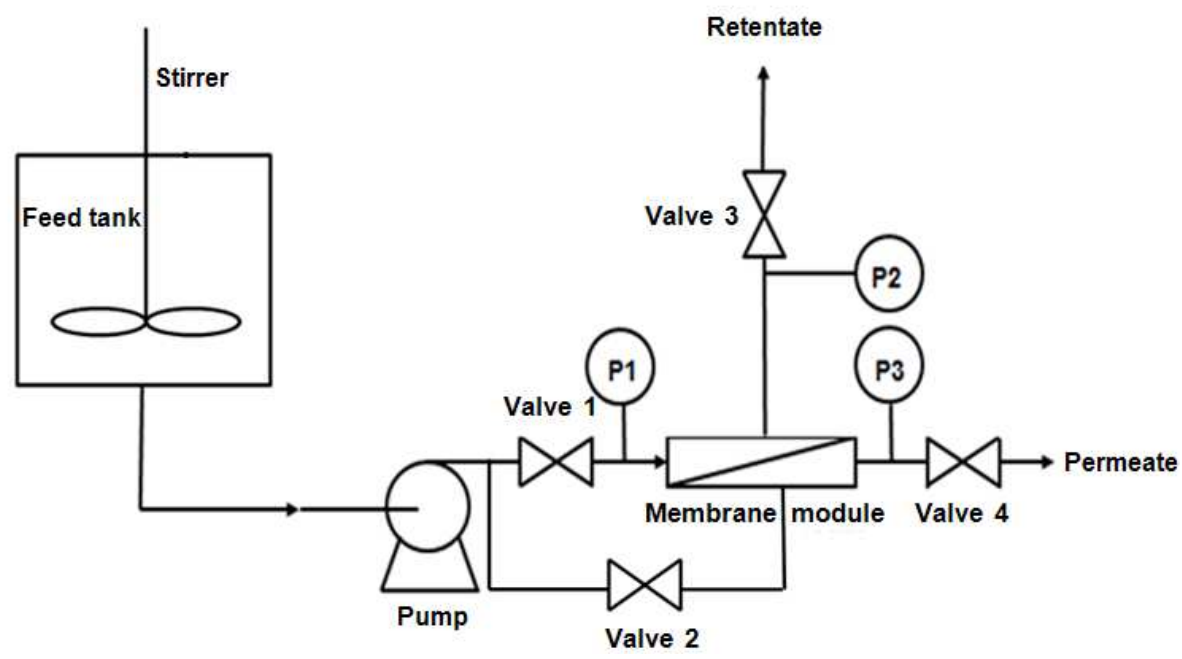

574

575

576

577

578

579
Fig. 1. Schematic diagram of the ceramic membrane filtration system, $P 1, P 2, P 3$ are manometers.

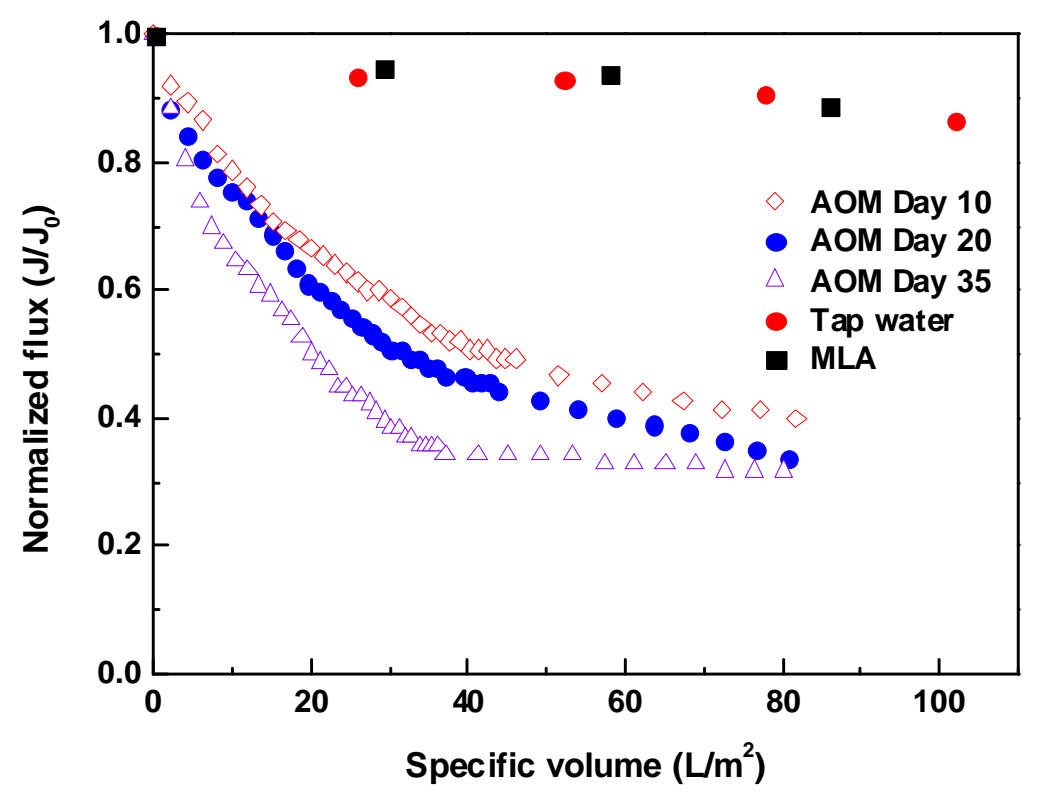

Fig. 2. Normalized flux vs. specific volume for the MF of tap water, MLA solution and the solutions containing AOM from different phases of $M$. aeruginosa growth. 


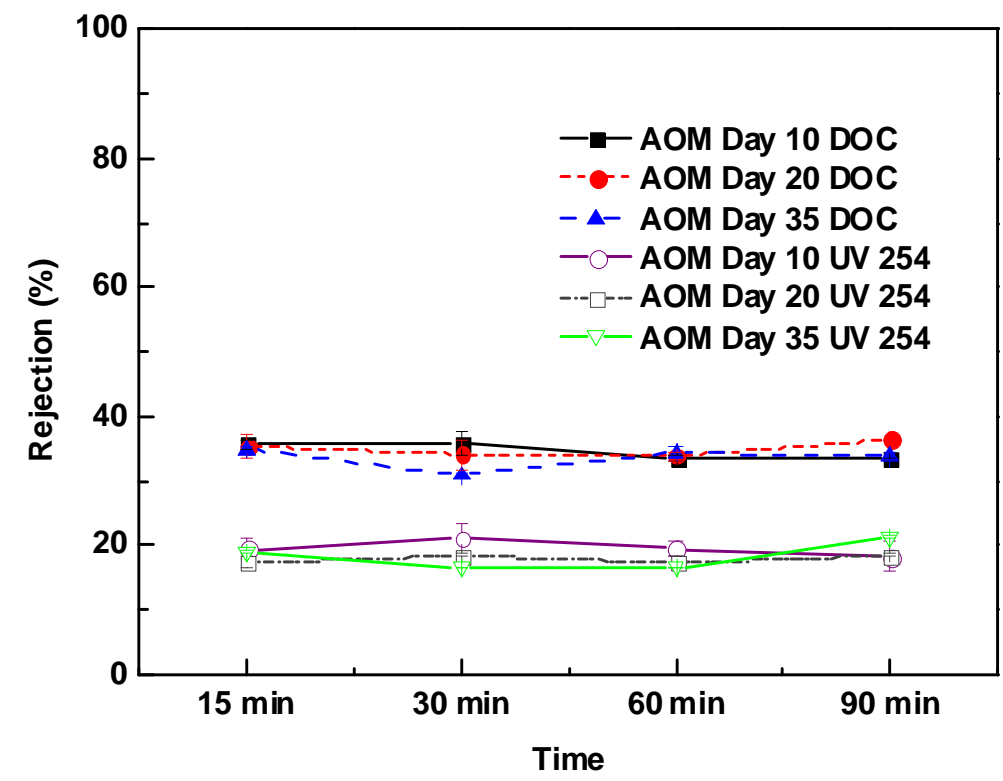

586

Fig. 3. $D O C$ and $U_{V A} A_{254}$ rejection during MF of the three AOM solutions.

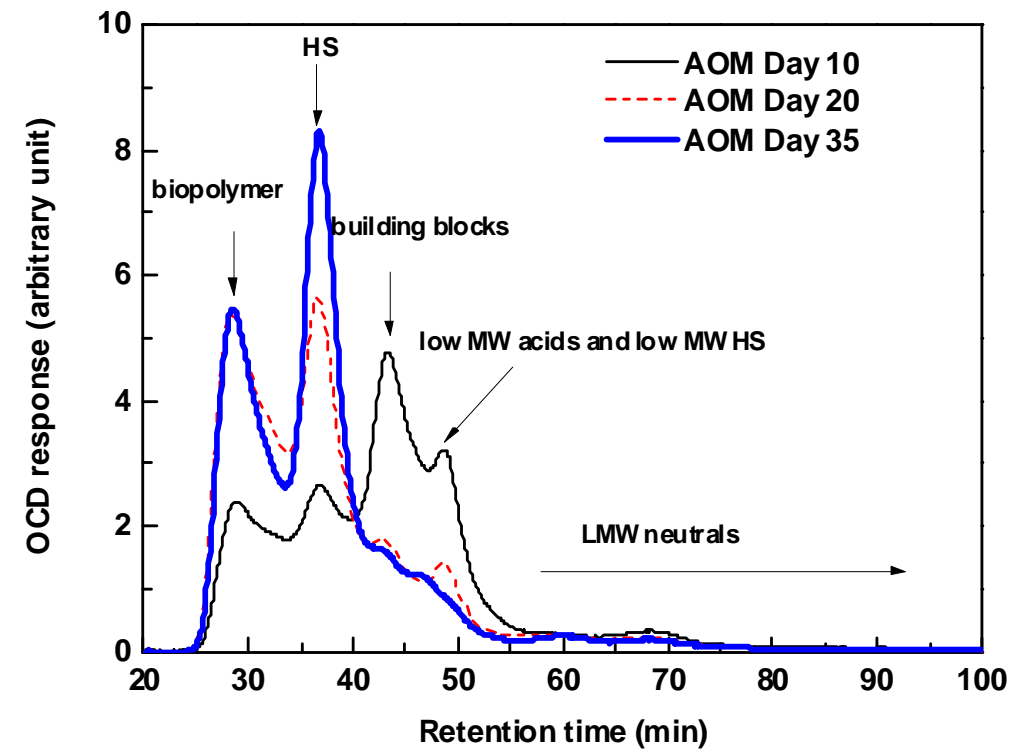

Fig. 4. LC-OCD chromatograms of the AOM from different phases of $M$. aeruginosa growth. $\mathrm{HS}=$ humic substances 

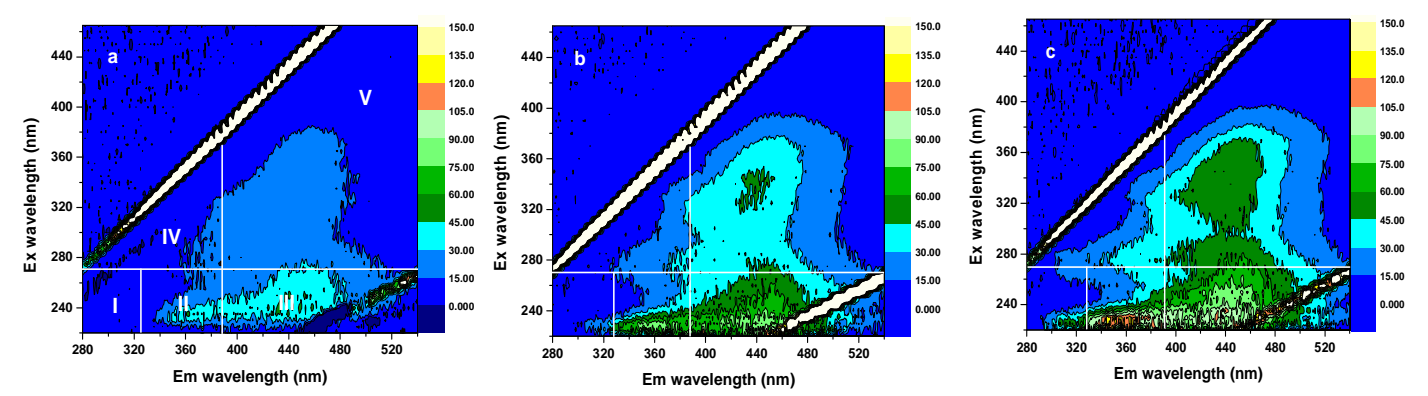

599

600

Fig. 5. Fluorescence EEM spectra of (a) Day 10, (b) Day 20 and (c) Day 35 AOM. Regions I

601 and II: aromatic proteins (AP); Region III: fulvic acid-like (FA); Region IV: soluble

602 microbial products (SMPs); Region V: humic acid-like (HA).

603

604

605

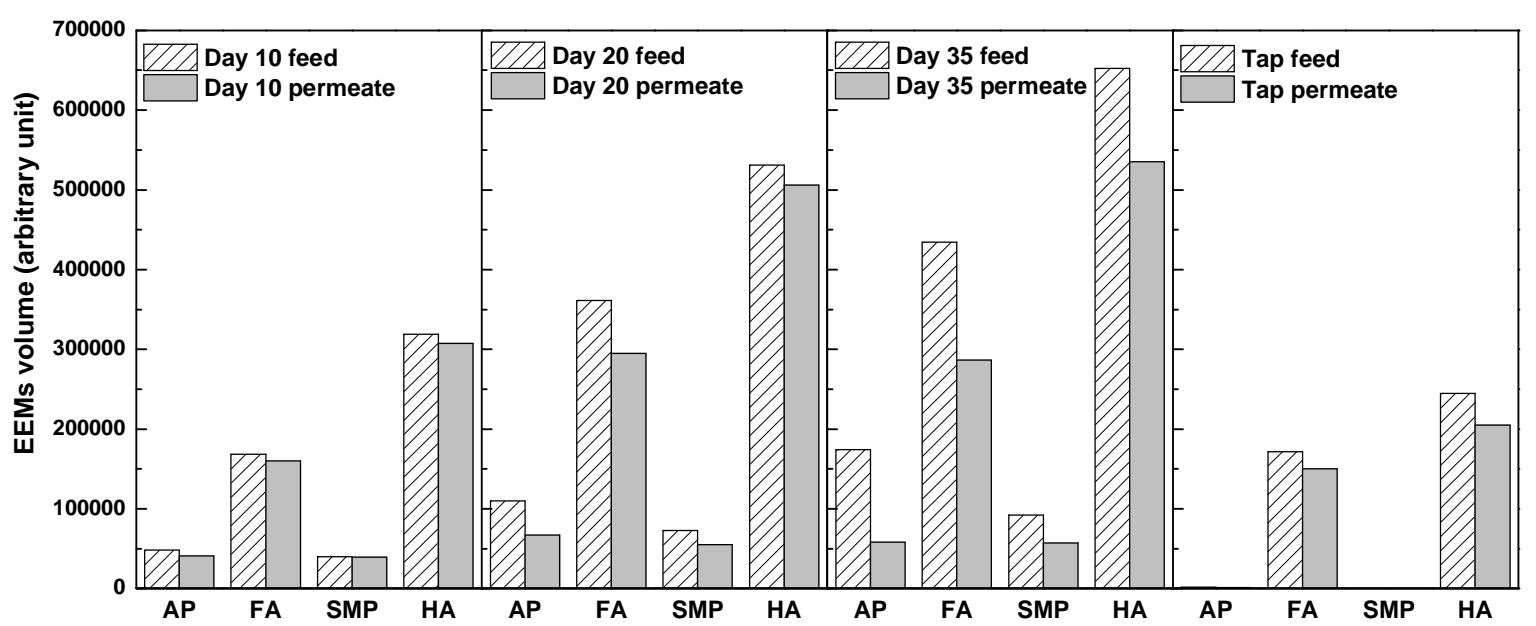

607

Fig. 6. EEM spectra volumes for the AOM and tap water before and after MF. 


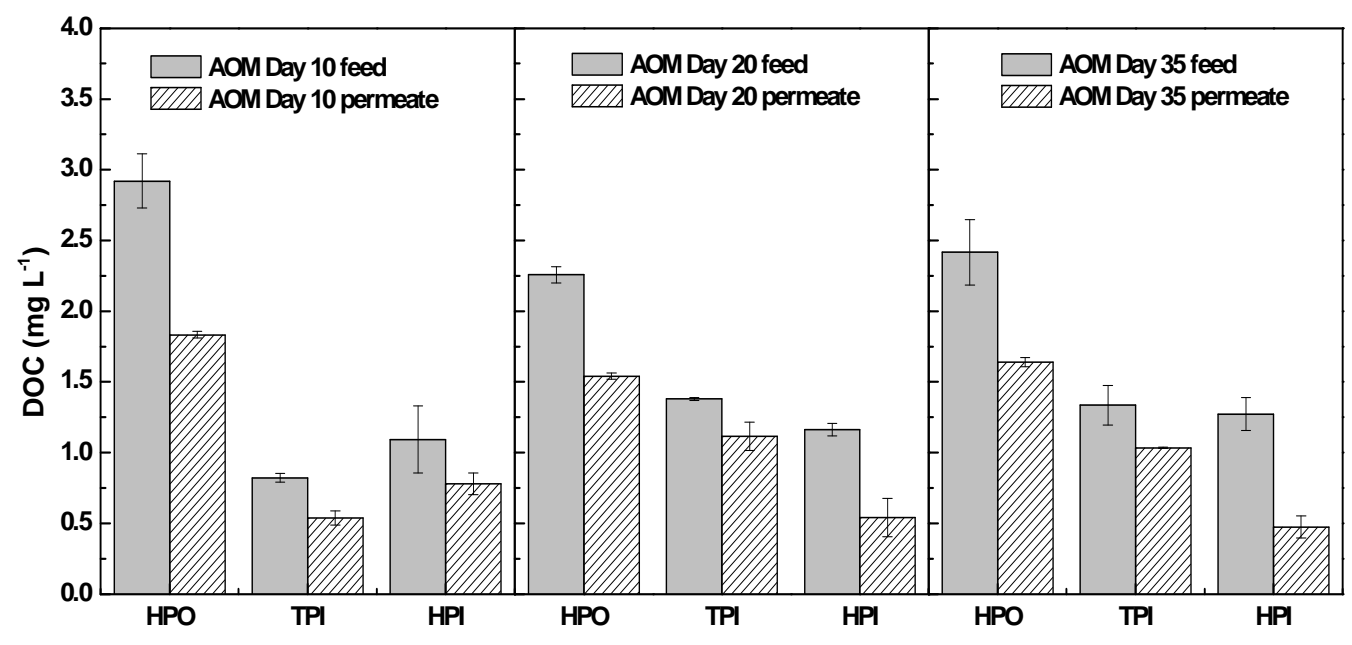

612

613 Fig. 7. Fractional components of AOM in MF feed and permeate. HPO: hydrophobic fraction; 614 TPI: transphilic fraction; HPI: hydrophilic fraction.

615

616

617

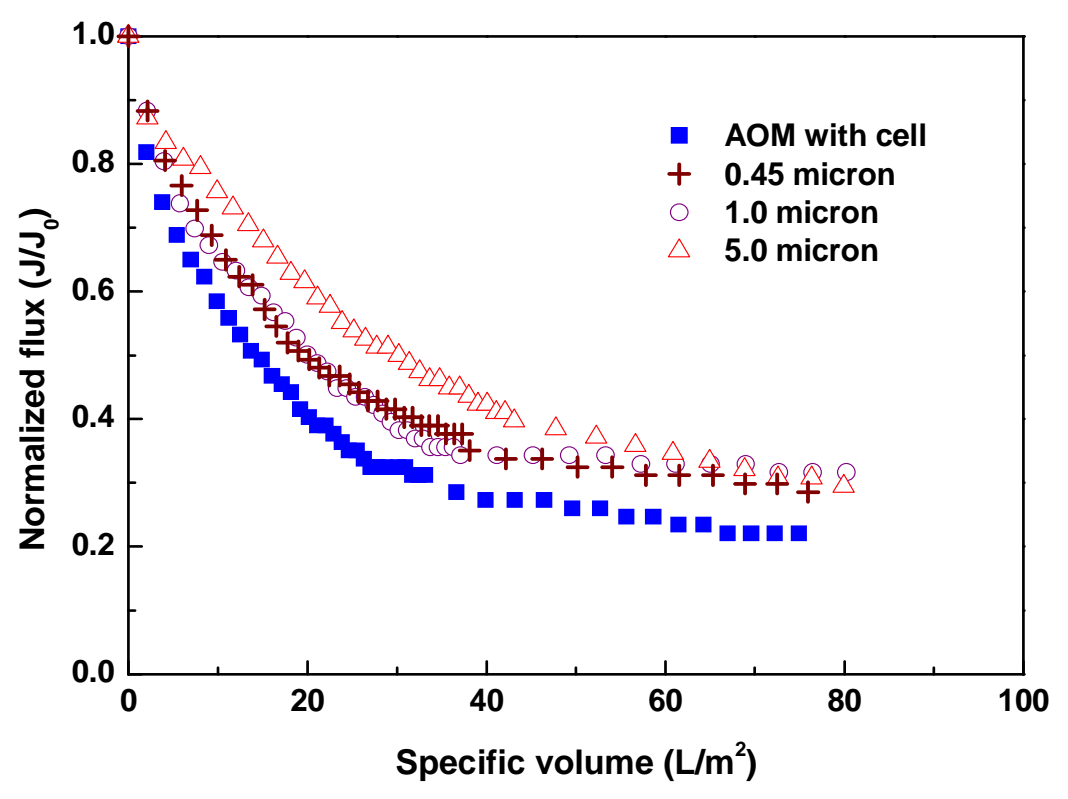

Fig. 8. Normalized flux vs. specific volume for the MF of the solutions of: 1) AOM with cells; 2) $0.45 \mu \mathrm{m}$ pre-filtered $\mathrm{AOM}$; 3) $1.0 \mu \mathrm{m}$ pre-filtered $\mathrm{AOM}$; 4) $5.0 \mu \mathrm{m}$ pre-filtered AOM. (All feed solutions contained AOM extracted from stationary phase) 


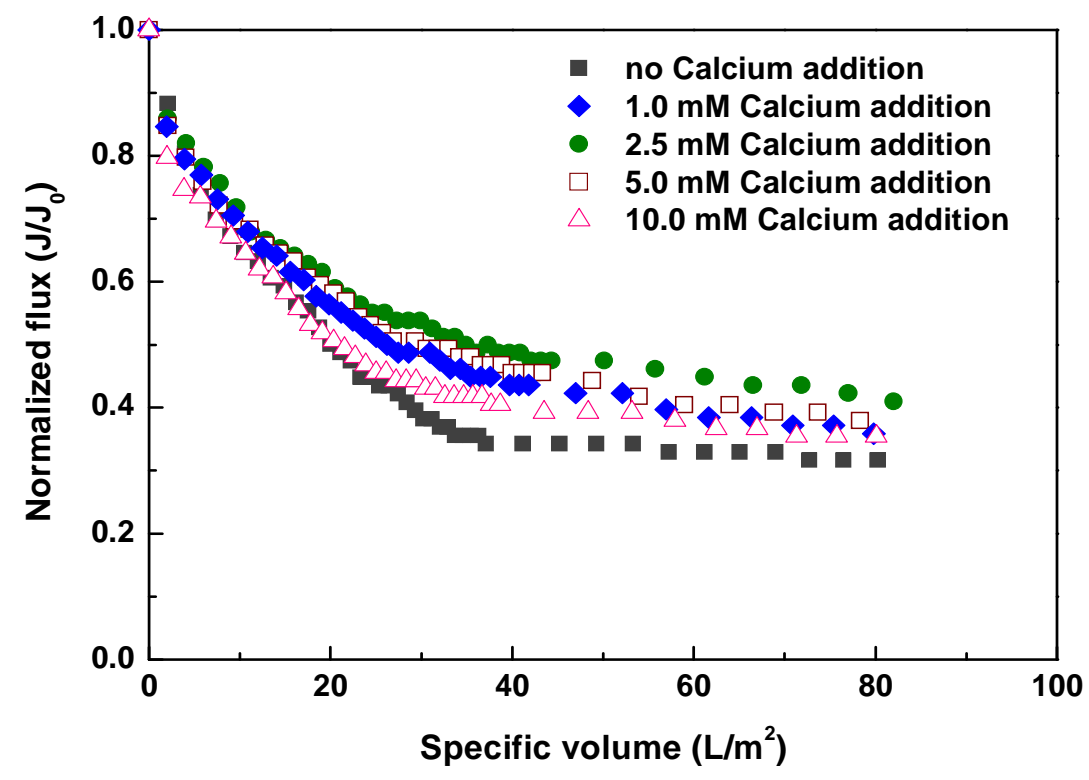

627

628

629

Fig. 9. Normalized flux vs. specific volume for the MF of AOM (stationary phase) solutions with and without addition of calcium.

630 